\title{
Computational Fluid Dynamic Analysis of the Flow around the Pivot Bearing of the Centrifugal Ventricular Assist Device* (Effects of Design Variations of the Washout Hole, the Pivot and the Back Gap)
}

\author{
Masahiro NISHIDA**, Takashi YAMANE**, Osamu MARUYAMA**, Yoshiyuki SANKAI ${ }^{* * *}$ and \\ Tatsuo TSUTSUI ${ }^{* * * *}$
}

\begin{abstract}
Flow mechanisms within a monopivot centrifugal pump were clarified in order to prevent stagnation around the pivot bearing, which may cause thrombogenesis. We focused on the geometric effects of the pump, which included the effects of the washout hole diameter, the pivot friction area and the back gap width of the impeller relative to the washout around the pivot bearing. Flow patterns were carefully examined around the pivot bearing, including the region inside the washout hole and the back gap of the impeller, by computational fluid dynamic analysis. Based on the results from the computational fluid dynamic analyses, we found that a balance relationship between the washout hole diameter and the back gap width of the impeller affected the secondary flow toward the pivot bearing that eliminated the stagnation around the pivot bearing. In addition, while increasing in the pivot friction area eliminated stagnation around the pivot bearing, it also increased hemolysis within the pump.
\end{abstract}

Key Words: Computational Fluid Dynamics, Turbomachinery, Medical Engineering, Medical Equipment, Bio-Fluid Engineering

\section{Introduction}

Thrombogenesis is one of the most important problems from a fluid mechanical point of view, preventing the development of blood pumps. Thrombogenesis is closely related to low-shear flow or stagnation on the surface of the artificial material ${ }^{(1)}$. Therefore, many researchers have investigated the flow inside blood pumps using computational fluid dynamics (CFD) analysis in order to prevent thrombogenesis ${ }^{(2)-(6)}$.

In our laboratory, we have developed a monopivot centrifugal pump as a ventricular assist device ${ }^{(7)}$. In this pump, an impeller is supported by a pivot bearing in order to prevent stagnation around the bearing, which may in turn cause thrombus formation. However, since stagnation

\footnotetext{
* Received 7th July, 2005 (No. 05-4090)

** Institute for Human Science and Biomedical Engineering, National Institute of Advanced Industrial Science and Technology, 1-2-1 Namiki, Tsukuba 305-8564, Japan

*** Institute of Engineering Mechanics and Systems, University of Tsukuba, 1-1-1 Tennoudai, Tsukuba 305-8573, Japan

**** Institute of Clinical Medicine, University of Tsukuba, 11-1 Tennoudai, Tsukuba 305-8575, Japan
}

most often occurs around the pivot bearing, washout effect should be obtained around the pivot bearing by washout holes through the impeller ${ }^{(8)}$. Therefore, the geometric optimization around the pivot bearing including the geometry of the washout hole is key to increasing the hemocompatibility of the monopivot centrifugal pump. In previous studies, we optimized the geometry from several pump models with various types of washout holes based on the relationship of the results from among flow visualization experiments $^{(9),(10)}$, CFD analyses ${ }^{(11)}$ and animal experiments. In the present study, we focused on the geometric effects that arose in response to the washout hole diameter, the pivot friction area and the back gap width of the impeller relative to the washout around the pivot bearing. The flow mechanism around the pivot bearing including in the washout hole and in the back gap of the impeller was clarified using the CFD method.

\section{Method}

\subsection{CFD analysis procedure}

Figure 1 shows the structure of the monopivot centrifugal pump. The impeller with permanent magnets is supported by a pivot bearing and is driven by rotating permanent magnets fixed to a motor shaft. This system 

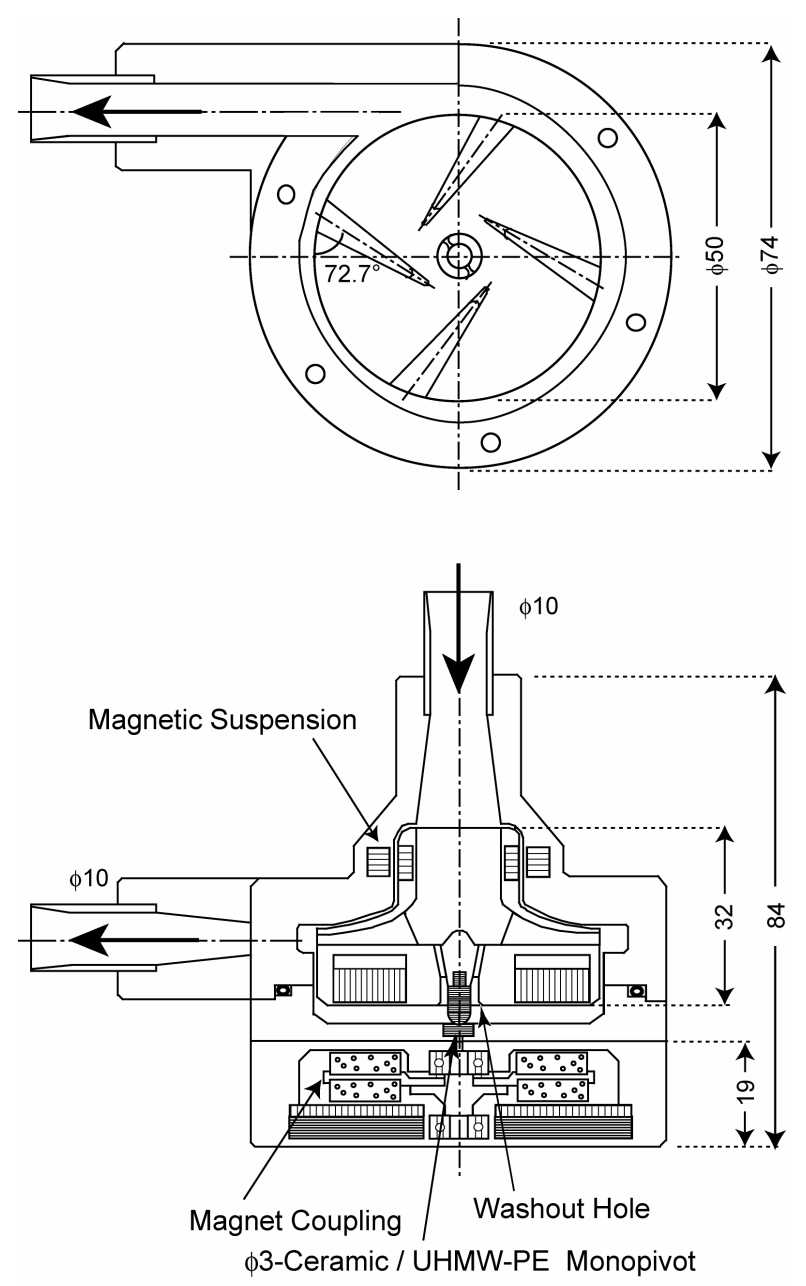

unit: $\mathrm{mm}$

Fig. 1 Structure of the monopivot centrifugal pump

was substituted for the direct drive system of our previous models ${ }^{(12)}$, in which the impeller itself was the rotor of the motor. The back gap width of the impeller could be increased in this system, e.g. to $1.6 \mathrm{~mm}$ or $2.6 \mathrm{~mm}$, because the magnetic flux became parallel to the shaft compared to that of the direct drive system.

Figure 2 shows the geometric parameters investigated in the present study. We focused on the washout hole diameter, the pivot friction area and the back gap width of the impeller as geometric parameters. Model DD7 was defined as the base model for the present study having a washout hole diameter of $9.8 \mathrm{~mm}$, a pivot friction area of $0 \mathrm{~mm}^{2}$ and a back gap width of the impeller of $0.6 \mathrm{~mm}$. Here, the pivot friction area of $0 \mathrm{~mm}^{2}$ means that the male and female pivots cause friction at a point. Table 1 shows the design variations of these parameters; (i) Washout hole diameter (DD7 and DD8 series): The flow was compared among models having various washout hole diameters. The washout hole diameter, $d$, was decreased from $9.8 \mathrm{~mm}$ to $9,8,7$ and $6 \mathrm{~mm}$, while the other geometric parameters were kept constant. The model with $d=7 \mathrm{~mm}$ appeared to realize a suitable flow for the blood pump and was referred

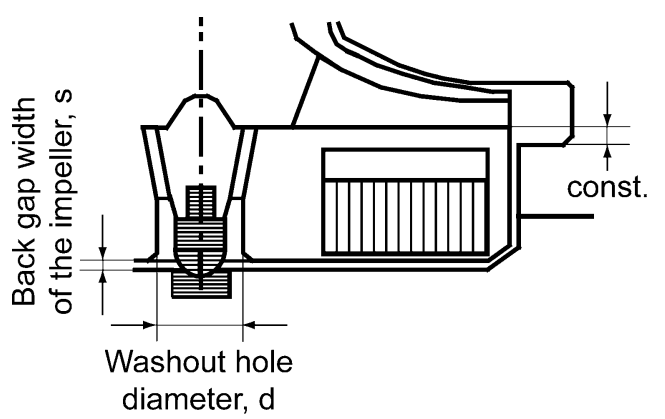

(a)

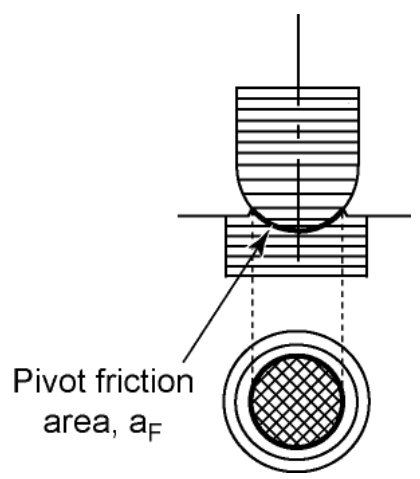

(b)

Fig. 2 Geometric parameters of the washout hole, the pivot bearing and the back gap of the impeller; (a) Washout hole diameter and the back gap width of the impeller, (b) Pivot friction area

Table 1 Variation of the design parameters of the present study

\begin{tabular}{|c|c|c|c|c|}
\hline ID & Name & $\begin{array}{c}\text { Washout hole } \\
\text { diameter, } \\
\text { d (mm) }\end{array}$ & $\begin{array}{c}\text { Pivot friction } \\
\text { area, } \mathrm{a}_{\mathrm{A}}\left(\mathrm{mm}^{2}\right)\end{array}$ & $\begin{array}{c}\text { Back gap } \\
\text { width, s (mm) }\end{array}$ \\
\hline$\# 1$ & DD7 & 9.8 & & \\
\hline$\# 2$ & DD7-9 & 9 & & \\
\hline \#3 & DD7-8 & 8 &.- & 0.6 \\
\hline \#4 & (DD7-7) & 7 & (point contact) & \\
\hline$\# 5$ & DD7-6 & 6 & & \\
\hline$(\# 4)$ & (DD8 $\quad$ (DD7-7)) & & 0 & \\
\hline$\# 6$ & DD10 (DD9D) & 7 & 1.6 & 06 \\
\hline$\# 7$ & DD9C & 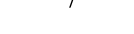 & 3.6 & 0.0 \\
\hline$\# 8$ & (DD9A) & & 8 & \\
\hline$(\# 6)$ & (DD10 (DD9D)) & & & 0.6 \\
\hline$\# 9$ & MC101A & 7 & 1.6 & 1.6 \\
\hline$\# 10$ & MC101 & & & 2.6 \\
\hline
\end{tabular}

to as model DD8. (ii) Pivot friction area (DD9 series): The flow was compared among models having various pivot friction areas. Since a pivot clearance was caused by a difference in the radii of curvature between the male and female pivots in model DD8, the clearance could be removed by the coincidence in the radii of curvature that forms the pivot friction area. The pivot friction area, $a_{F}$, increased from $0 \mathrm{~mm}^{2}$ (point friction) in model DD8 to $1.6,3.6$ and $8 \mathrm{~mm}^{2}$ by varying of the female pivot. In addition, we tested a model with $a_{F}=14 \mathrm{~mm}^{2}$, but it did not work. The former other parameter, $d$, was constant. The model with $a_{F}=1.6 \mathrm{~mm}^{2}$ appeared to realize a suitable flow, and was referred to as model DD10. (iii) Back gap 


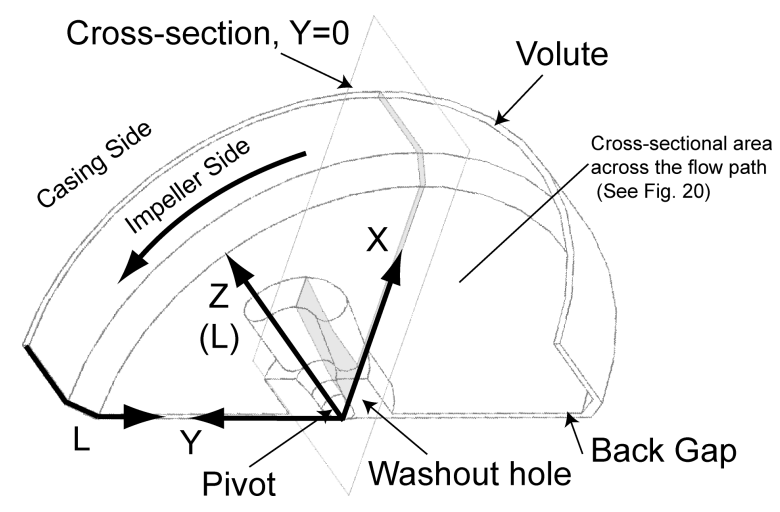

(a)

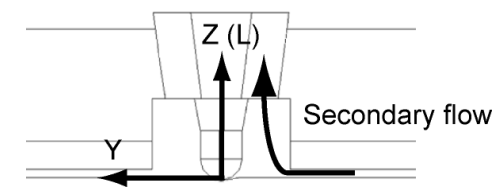

(b)

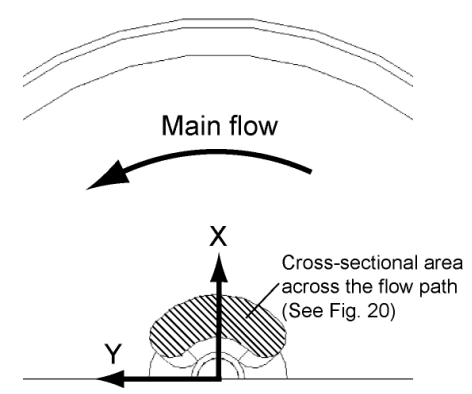

(c)

Fig. 3 CFD model and coordinate system: (a) airscape of the CFD model, (b) $X$ axis projection and (c) $Z$ axis projection

width of the impeller (DD10 series): The flow was compared among models having various back gap widths of the impeller. The back gap width of the impeller, $s$, was increased from $0.6 \mathrm{~mm}$ to 1.6 and $2.6 \mathrm{~mm}$. The former other parameters, $d$ and $a_{F}$, were constant. The model with $s=2.6 \mathrm{~mm}$ was referred to as model MC101. The relative positions between the back shroud and the volute were also identified (See Fig. 2 (a)).

Figure 3 shows the CFD model and the coordinate system used in this study. The flow was not analyzed in all regions of the pump being tested, but specifically in the regions around the bearing, including in the washout hole and in the back gap of the impeller for the CFD model. The grid generation was performed using the Gridgen software package (Pointwise, Texas, USA). The grid used was a structure-grid type with the size of the grid set at 0.01 or $0.02 \mathrm{~mm}$ in the thickness direction of the boundary layer and $0.08 \mathrm{~mm}$ in the direction across the discontinuous angular surface. Table 2 shows the number of cells for all analyses. The transfinite interpolate method was used for the grid generation and the elliptic partial differential equation method was applied for the grid smooth-
Table 2 Number of CFD cells

\begin{tabular}{|c|c|}
\hline ID & Number of cells \\
\hline$\# 1$ & 352,448 \\
$\# 2$ & 372,000 \\
$\# 3$ & 355,680 \\
$\# 4$ & 339,360 \\
$\# 5$ & 323,040 \\
\hline$\# 6$ & 298,960 \\
$\# 7$ & 270,160 \\
$\# 8$ & 251,680 \\
\hline$\# 9$ & 671,360 \\
$\# 10$ & 894,160 \\
\hline
\end{tabular}

ing shape by shape. The number of smoothing steps was usually 100 iterations, with 500 iterations employed in the cross-section for the washout hole. The calculation was performed by a finite volume method using STAR-CD commercial software (Computational Dynamics, London, UK). The specific gravity of blood was defined as 1, and the viscosity of the blood was defined as $0.003 \mathrm{~Pa} \cdot \mathrm{s}$. For the boundary conditions, we assumed that the pressure difference between the volute and the outlet of the washout hole was equal to the pump head at $100 \mathrm{mmHg}$ which combined with a rotational impeller speed of $1900 \mathrm{rpm}$, enabled a pump flow rate of $5 \mathrm{~L} / \mathrm{min}$. The cyclic boundary was used for the 180-degree in the rotational direction. The calculation was conducted as a laminar flow and the solution was processed with the double precision, and using the SIMPLE method with the AMG method for the solution algorithm. The relaxation factor was set to be small so that the solution would converge easily. The iterations were continued until the pressure converged, as in our previous study ${ }^{(11)}$.

After arriving at a solution, the flow rate through the washout hole and the back gap of the impeller, $\Delta Q_{b}$, was calculated as the sum of the product of the cell crosssection across the axis of the washout hole and the velocity component along the axis. The wall shear stress, $\tau$, was calculated by dividing the shear force on a cell surface on the wall by the area of the surface.

\subsection{Hemolysis test procedure}

Hemolysis tests were conducted focally for the model DD9 series. In tests, heparinized fresh bovine blood was used with the hematocrit of the blood adjusted to $30 \%$ using saline. The driving conditions were a head of $100 \mathrm{mmHg}$ and a flow rate of $5 \mathrm{~L} / \mathrm{min}$ for 4 hours at room temperature using a mock circulation system. During the test, blood was sampled from the system and plasma was obtained after centrifuging. The concentration of free hemoglobin was then determined spectrophotometrically using the tetramethylbenzidine (TMB) method. The normalized index of hemolysis (NIH) was calculated from the hemoglobin concentration normalized by the flow rate, 
experimental time, total blood volume and hematocrit ${ }^{(14)}$. The results were produced in a single test in each case. Each NIH was compared with that obtained using a commercial pump BP-80 (Medtronic, Inc., Shoreview, U.S.A.) as relative evaluation.

\subsection{Anti-thrombogenecity test procedure}

The anti-thrombogenecity tests were performed for 4-7 days using sheep with several pump models: DD7, DD8 (DD7-7), DD9 (DD9A) and MC101. Each pump model test was performed several times as shown in Table 3. The activated clotting time (ACT) was maintained at approximately 200 seconds by heparin. The antithrombogenecity was judged visually.

\section{Results}

\subsection{Effect of the washout hole diameter on flow}

Figure 4 shows the velocity distribution of the secondary flow (UW component on cross-section $Y=0$ that crosses through the center of the washout hole, See Fig. 3) in model DD7. The secondary flow from the volute to the outlet of the washout hole caused by the pressure gradient between the volute, the pressure of which was set to be $100 \mathrm{mmHg}$, which provided the driving force, and the outlet of the washout hole, the pressure of which was set to be $0 \mathrm{mmHg}$.

Figure 5 shows the effect of the washout hole diameter on the flow rate through the washout hole and the back gap of the impeller in the model DD7 and DD8 series. The flow rate through the washout hole and the back gap of the impeller was $1.4 \mathrm{~L} / \mathrm{min}$, which was approximately $30 \%$ of the pump flow when the washout hole diameter was $9.8 \mathrm{~mm}$. The flow rate decreased as the washout hole diameter decreased. The flow rate was $1.0 \mathrm{~L} / \mathrm{min}$ when the washout hole diameter was $7 \mathrm{~mm}$ and $0.86 \mathrm{~L} / \mathrm{min}$ when the washout hole diameter was $6 \mathrm{~mm}$.

Figure 6 shows the effect of the washout hole diameter on the velocity distribution of the secondary flow around the pivot bearing in the model DD7 and DD8 series. Figure 6 plots the velocity vector distribution of the secondary flow and the contour lines of the secondary velocity amplitude of $0.3 \mathrm{~m} / \mathrm{s}$, which is considered to be the threshold level separating low and high secondary-flowvelocity. The secondary flow velocity was small around the pivot bearing when the washout hole diameter was $9.8 \mathrm{~mm}$. Here, the region of low secondary flow velocity of less than $0.3 \mathrm{~m} / \mathrm{s}$ occupied the area where the radial distance from the center of the pivot bearing was approximately $2 \mathrm{~mm}$ (Fig. 6 (a)). The secondary flow velocity increased and the pivot bearing was washed out as the washout hole diameter was decreased from $9.8 \mathrm{~mm}$ to $6 \mathrm{~mm}$. This was due to the back gap region of the impeller approaching the pivot bearing despite decreased flow rate through the washout hole and the back gap of the impeller, as shown in Fig. 5. It was suggested that the strength of

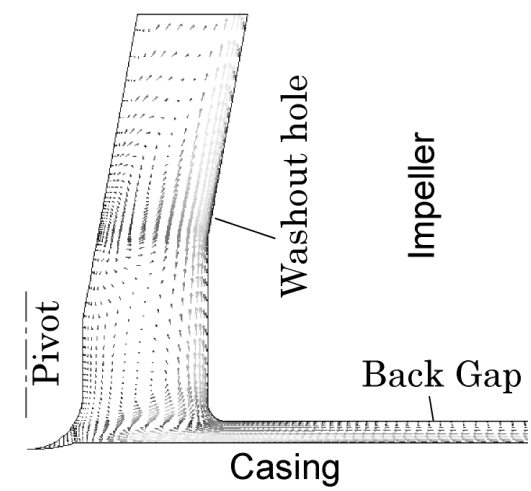

Fig. 4 Velocity distribution of secondary flow in model DD7

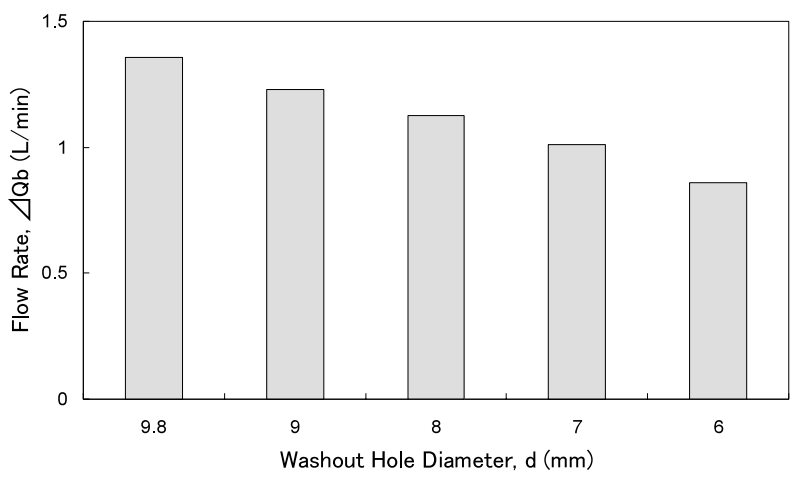

Fig. 5 Effect of the washout hole diameter on the flow rate through the washout hole and the back gap of the impeller in the model DD7 and DD8 series (ID: \#1 \#5 in Table 1. Pivot friction area, $a_{F}=0 \mathrm{~mm}^{2}$. Back gap width of the impeller, $s=0.6 \mathrm{~mm}$ )

the secondary flow around the pivot depended more on the effect of the distance from the back gap region to the pivot bearing than on the effect of the flow rate through the washout hole and the back gap of the impeller. The regions of low secondary flow velocity of less than $0.3 \mathrm{~m} / \mathrm{s}$ were located such that the radial distance from the center of the pivot bearing was approximately $1 \mathrm{~mm}$ when the washout hole diameter was either $7 \mathrm{~mm}$ or $6 \mathrm{~mm}$ (Fig. 6 (d) and (e)). However, the region of low secondary flow velocity around the pivot bearing did not decreased remarkably in size from the model with the washout hole diameter of $7 \mathrm{~mm}$ to that with the washout hole diameter of $6 \mathrm{~mm}$.

Figure 7 shows the effect of the washout hole diameter on the wall shear stress contour around the pivot bearing at the impeller side in the model DD7 and DD8 series. In model DD7, the stagnant region located around the pivot bearing (Fig. 7 (a)), when the wall shear stress was less than $5 \mathrm{~Pa}$ (approximately $1700 / \mathrm{sec})^{(11)}$. In the model, the wall shear stress was approximately 15 to $20 \mathrm{~Pa}$ and was slightly higher at the center of the pivot bearing than around the pivot. The wall shear stress around the pivot bearing obviously increased as the washout hole diameter decreased from 9.8 to $6 \mathrm{~mm}$. This was reflected by the 
(a)
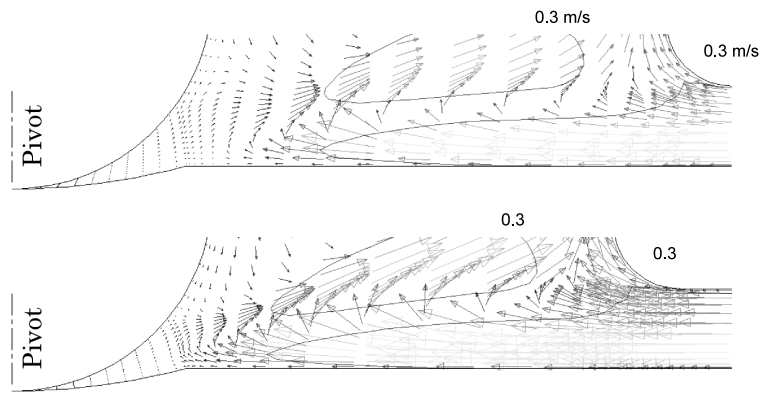

(b)

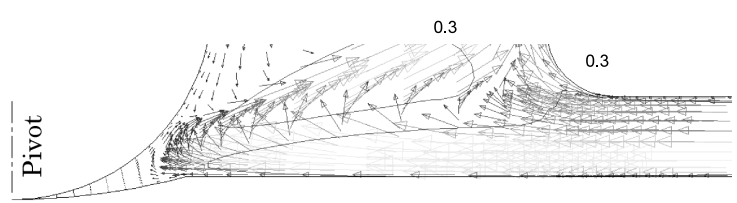

(c)

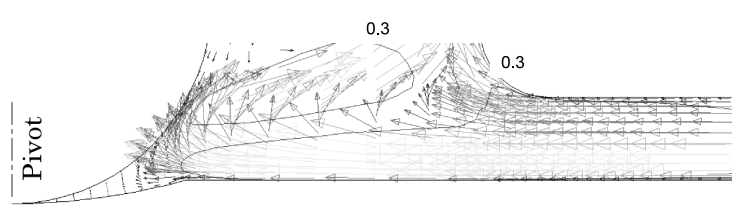

(d)

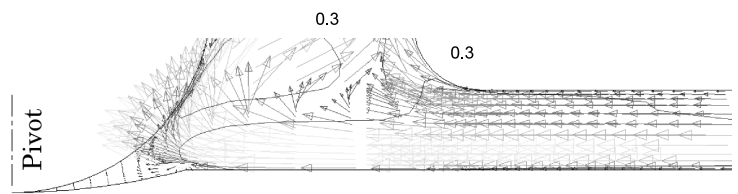

(e)

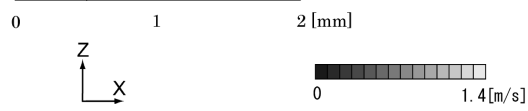

Fig. 6 Effect of the washout hole diameter on the secondary velocity distribution around the pivot bearing in the model DD7 and DD8 series; (a) Washout hole diameter, $d=9.8 \mathrm{~mm}$ (model DD7), (b) $d=9 \mathrm{~mm}$, (c) $d=8 \mathrm{~mm}$, (d) $d=7 \mathrm{~mm}$ (model DD8) and (e) $d=6 \mathrm{~mm}$

secondary flow velocity as shown in Fig. 6. The wall shear stress reached over $70 \mathrm{~Pa}$ in some regions around the pivot bearing when the washout hole diameter was 7 or $6 \mathrm{~mm}$. However, the stagnant region remained around the pivot bearing in both models.

Figure 9 shows the effect of the washout hole diameter on the wall shear stress in the model DD7 and DD8 series. In order to clarify the quantities of the previous wall shear stress contour, an area histogram of the wall shear stress was produced for every $5 \mathrm{~Pa}$, the objective area of which was limited to the surface of the male pivot in contact with the blood, as shown in Fig. 8. Here, $a_{B}$ denotes total surface area of the male pivot contacting with blood. The histogram peak of the wall shear stress increased from $0-5 \mathrm{~Pa}$ to $0-5,15-20,10-15$ and $15-20 \mathrm{~Pa}$ as the washout hole diameter was decreased from $9.8 \mathrm{~mm}$ to $9,8,7$ and $6 \mathrm{~mm}$, respectively. The stagnant region on the surface of the male pivot located in all models in this model series remained approximately constant as the washout hole diameter was decreased to less than $7 \mathrm{~mm}$. On the other hand, the high-shear (over $70 \mathrm{~Pa}$ ) region, which usually causes inefficiency due to the regional disparity of the amount of shear, increased.

The secondary flow washed out the pivot bearing more strongly as the washout hole diameter was decreased until $7 \mathrm{~mm}$, as shown in Fig. 6. Therefore, the model having a washout hole diameter of $7 \mathrm{~mm}$ or less was considered to be better with respect to pivot washout. On the other hand, the flow rate through the washout hole decreased as the washout hole diameter decreased. Therefore, the model having a larger diameter washout hole was considered to be better with respect to the total washout through the washout hole and the back gap of the impeller. This is because the larger flow rate through the washout hole and the back gap of the impeller should be considered to inhibit thrombus formation by allowing sufficient flow circulation. When we consider the balance between the pivot washout effect and the flow circulation effect through the washout hole and the back gap of the impeller, the model having a washout hole diameter of $7 \mathrm{~mm}$ was considered to be the best model in this model series based on the above-mentioned considerations, although the occurrence of the stagnant region around the pivot bearing has not yet been resolved.

\subsection{Effect of the pivot friction area on flow and the hemolysis test results}

Figure 10 shows the effect of the pivot friction area on the flow rate through the washout hole and the back gap of the impeller in the model DD9 series. The flow rate through the washout hole and the back gap of the impeller was approximately constant around at $1.0 \mathrm{~L} / \mathrm{min}$ in this model series, irrespective of the pivot friction area. Therefore, the effect of the pivot friction area on the flow rate through the washout hole and the back gap of the impeller was understood to be negligible.

Figure 11 shows the effect of the pivot friction area on the velocity distribution of the secondary flow around the pivot bearing in the model DD9 series. The region in the pivot clearance formed a wedge-shaped region that caused stagnation for the secondary flow. The region in the pivot clearance decreased as the pivot friction area increased from 0 to $8 \mathrm{~mm}^{2}$. Therefore, the stagnant region in close proximity to the pivot friction region decreased as the pivot friction area increased.

Figure 12 shows the effect of the pivot friction area on the wall shear stress contour around the pivot bearing at the impeller side in the model DD9 series. A slightly stagnant region occurred in close proximity to the pivot friction region when the pivot friction area was 0 or $1.6 \mathrm{~mm}^{2}$. However, this stagnant region disappeared when the pivot friction area was 3.6 or $8 \mathrm{~mm}^{2}$. On the other hand, the region except for that in close proximity to the pivot friction region was only slightly affected by the geometry in close proximity to the pivot bearing. 


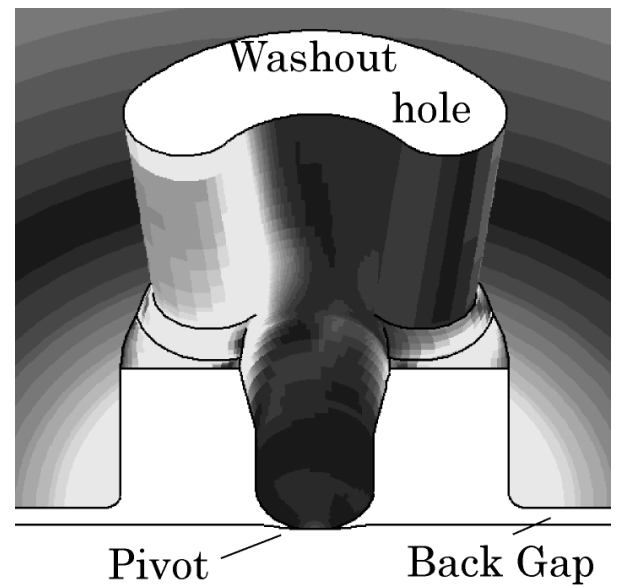

(a)

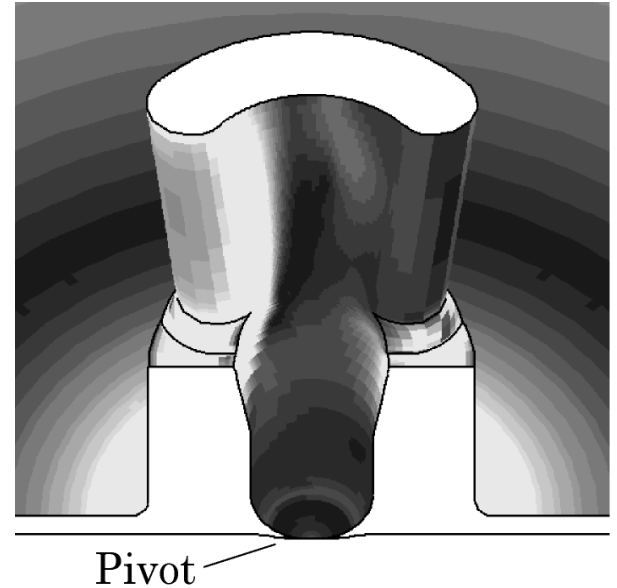

(c)

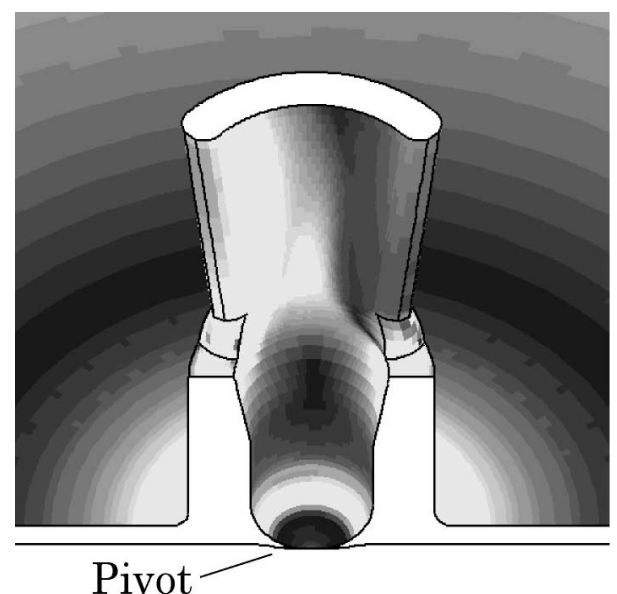

(e)

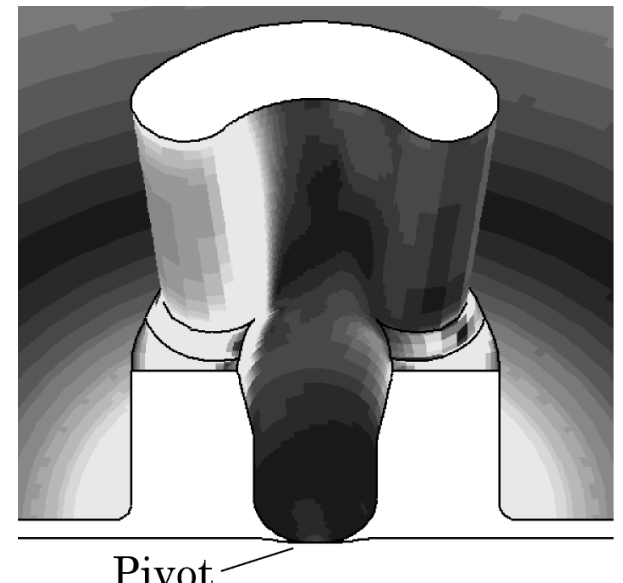

(b)

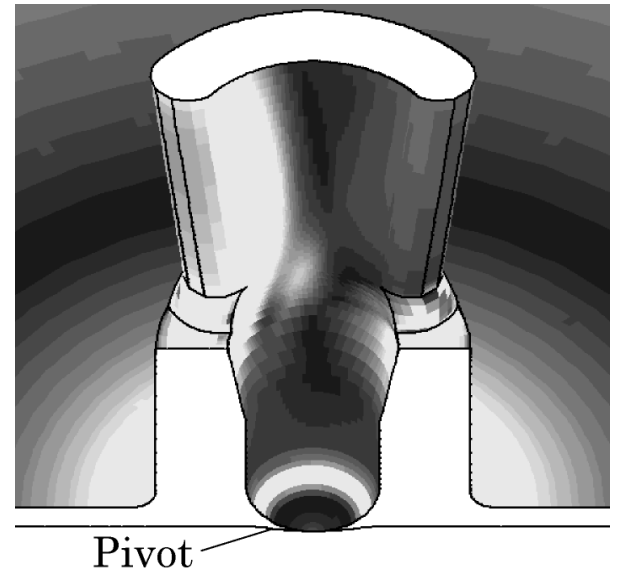

(d)
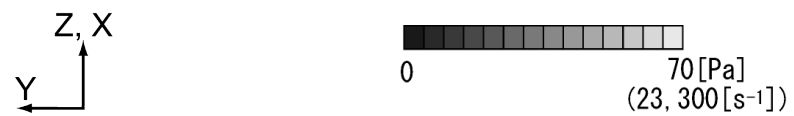

Fig. 7 Effect of the washout hole diameter on the wall shear stress contour around the pivot bearing in the model DD7 and DD8 series; (a) Washout hole diameter, $d=9.8 \mathrm{~mm}$ (model DD7), (b) $d=9 \mathrm{~mm}$, (c) $d=8 \mathrm{~mm}$, (d) $d=7 \mathrm{~mm}$ (model DD8) and (e) $d=6 \mathrm{~mm}$

The area histogram in Fig. 13 shows the effect of the pivot friction area on the wall shear stress on the surface of the male pivot in the model DD9 series. The histogram peak of the wall shear stress was 5-15 $\mathrm{Pa}$ when the pivot friction area was $0 \mathrm{~mm}^{2}$ and was $10-20 \mathrm{~Pa}$ when the pivot friction area was larger than $1.6 \mathrm{~mm}^{2}$. The wall shear stress increased from $0-5 \mathrm{~Pa}$ to $0-5,15-20$ and $75-$ $80 \mathrm{~Pa}$ in the closest proximity to the pivot clearance as the 


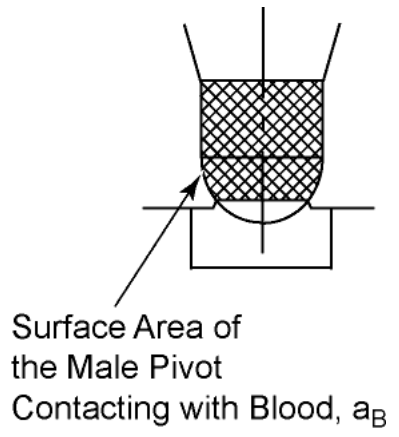

Fig. 8 Surface area of the male pivot in contact with the blood

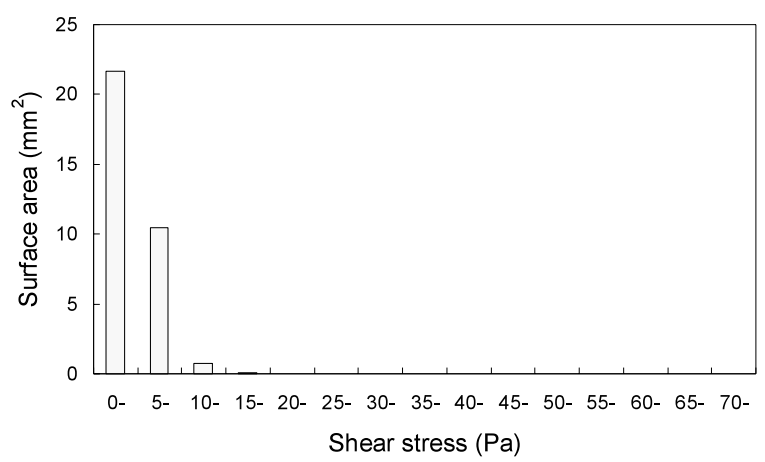

(a)

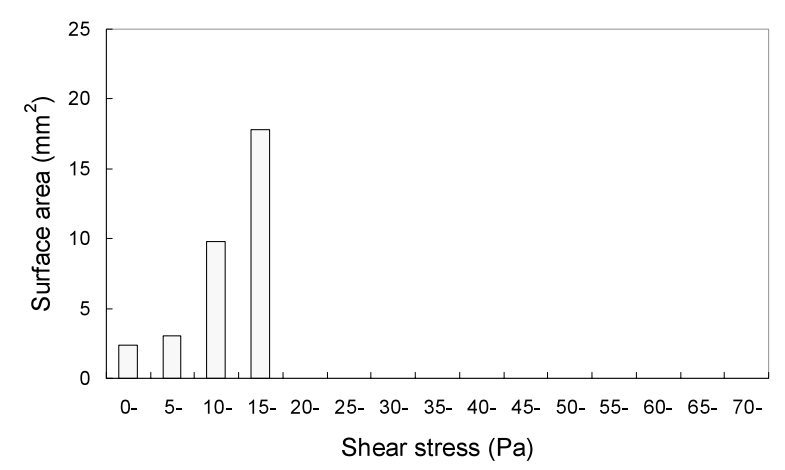

(c) pivot friction area was increased from $0 \mathrm{~mm}^{2}$ to $1.6,3.6$ and $8 \mathrm{~mm}^{2}$, respectively. A slightly stagnant region occurred on the area histogram when the pivot friction area was $8 \mathrm{~mm}^{2}$. However, this region was located far from the pivot friction area, as shown in Fig. 12 (d). As such, this stagnation was considered unlikely to lead to thrombogenesis.

Figure 14 shows the effect of the pivot friction area on the Normalized Index of Hemolysis (NIH) values resulting from hemolysis tests in the model DD9 series ${ }^{(13)}$. The hemolysis obviously increased as the pivot friction area increased.

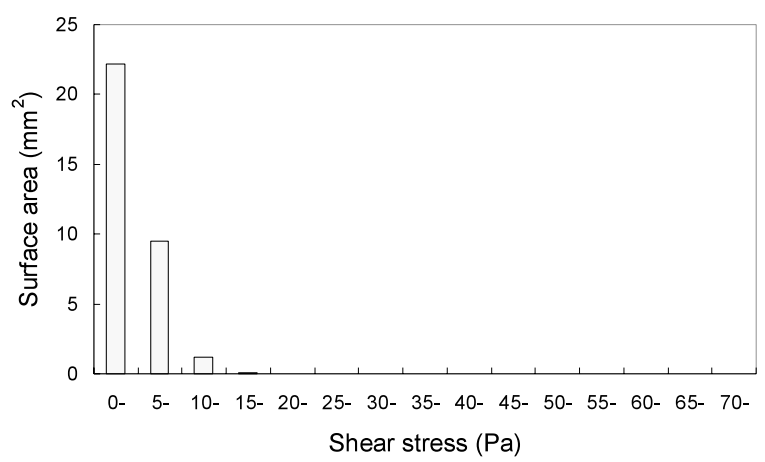

(b)

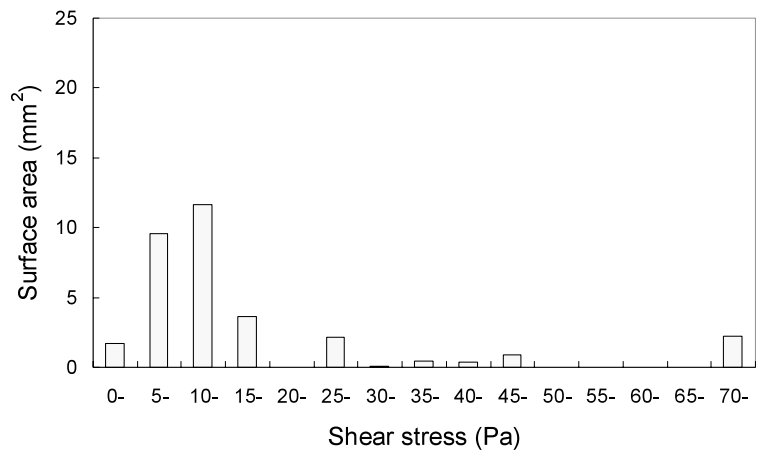

(d)

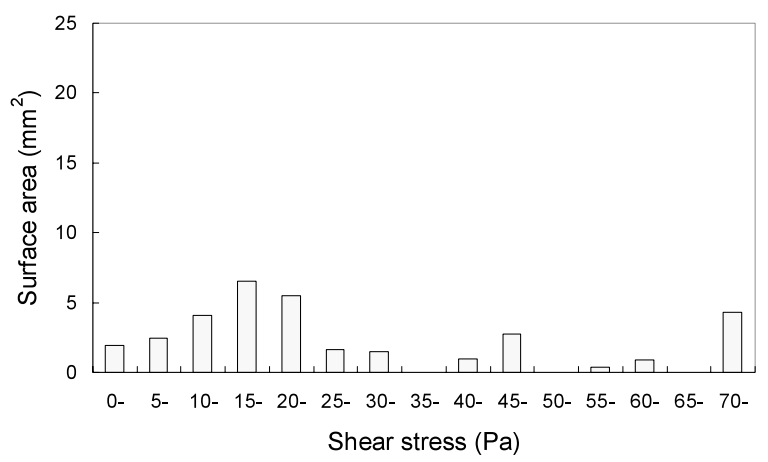

(e)

Fig. 9 Effect of the washout hole diameter on the area histogram of the wall shear stress on the surface of the pivot bearing in the model DD7 and DD8 series (Surface area of the male pivot contacting blood, $a_{B}=33 \mathrm{~mm}^{2}$ ); (a) Washout hole diameter, $d=9.8 \mathrm{~mm}$ (model DD7), (b) $d=9 \mathrm{~mm}$, (c) $d=8 \mathrm{~mm}$, (d) $d=7 \mathrm{~mm}$ (model DD8) and (e) $d=6 \mathrm{~mm}$ 


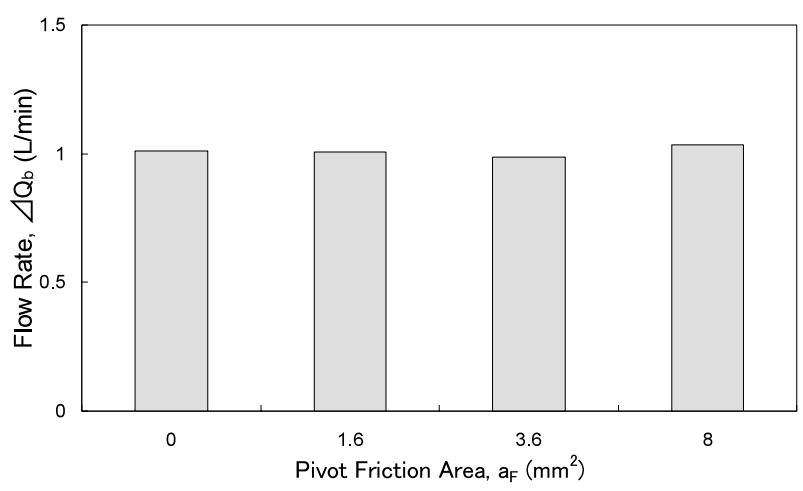

Fig. 10 Effect of the pivot friction area on the flow rate through the washout hole and the back gap of the impeller in the model DD9 series (\#4 and \#6-\#8 in Table 1. Washout hole diameter, $d=7 \mathrm{~mm}$. Back gap width of the impeller, $s=0.6 \mathrm{~mm}$ )

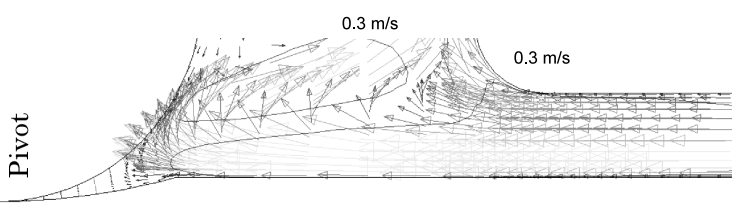

(a)

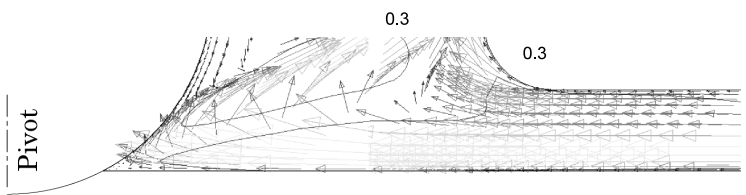

(b)

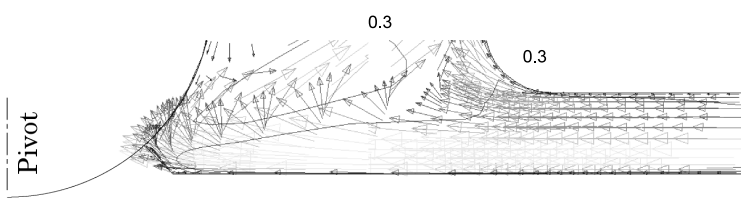

(c)

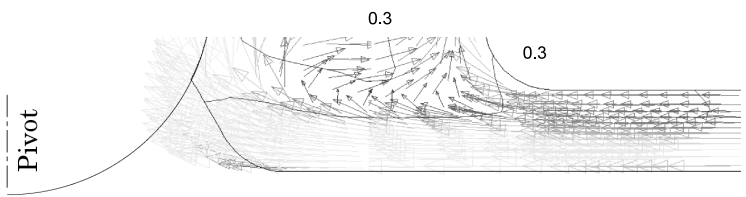

(d)

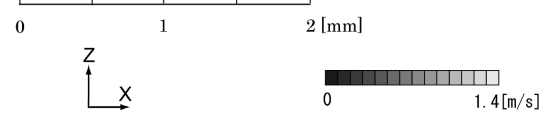

Fig. 11 Effect of the pivot friction area on the secondary velocity distribution around the pivot bearing in the model DD9 series; (a) Pivot friction area, $a_{F}=0 \mathrm{~mm}^{2}$ (model DD8), (b) $a_{F}=1.6 \mathrm{~mm}^{2}$ (model DD10), (c) $a_{F}=3.6 \mathrm{~mm}^{2}$ and (d) $a_{F}=8 \mathrm{~mm}^{2}$ (model DD9)

\subsection{Effect of the back gap width of the impeller on the flow}

Figure 15 shows the effect of the back gap width of the impeller on the flow rate through the washout hole and the back gap of the impeller in the model DD10 series. The flow rate through the washout hole and the back gap of the impeller increased as the back gap width of the impeller increased from $0.6 \mathrm{~mm}$ to 1.6 and $2.6 \mathrm{~mm}$. This was considered to be because the flow resistance in the back gap of the impeller decreased as the back gap width of the impeller increased.

Figure 16 shows the effect of the back gap width of the impeller on the velocity distribution of the secondary flow around the pivot bearing in the model DD10 series. The secondary flow around the pivot bearing washed out the region in close proximity to the pivot bearing. The secondary flow around the pivot appeared to be small when the back gap width of the impeller was $1.6 \mathrm{~mm}$. However, the secondary flow was not necessarily small in this model because the secondary flow had various strengths in the circumferential direction around the pivot, as predicted based on the post-scribed wall shear stress contour around the pivot bearing.

Even when the back gap width of the impeller was $2.6 \mathrm{~mm}$, the secondary flow was not small. This depended on the following geometric property against the secondary flow around the pivot. Figure 17 shows the velocity distribution of the secondary flow when the back gap width of the impeller was $2.6 \mathrm{~mm}$. As shown in Fig. 17, the secondary flow concentrated in a layer ranging $0.5 \mathrm{~mm}$ from the casing wall in the back gap of the impeller. This was considered to be because the fluid received a centrifugal force by the impeller rotation that moved the fluid outward in a layer ranging over $0.5 \mathrm{~mm}$ from the casing wall. The fluid only received a pressure gradient that moved the fluid inward, resulting in concentrating the fluid in a layer of approximately $0.5 \mathrm{~mm}$ from the casing wall. The existence of the concentrating secondary flow close to the casing wall appeared to be the reason why the secondary flow around the pivot did not decrease greatly, even if the back gap width of the impeller increased from 0.6 to $2.6 \mathrm{~mm}$.

Figure 18 shows the effect of the back gap width of the impeller on the wall shear stress contour around the pivot bearing on the impeller side in the model DD10 series. It was found that the region in close proximity to the pivot friction region was washed out by the secondary flow concentrated in a layer approximately $0.5 \mathrm{~mm}$ from the casing wall in the back gap of the impeller, even when the back gap width of the impeller was 1.6 or $2.6 \mathrm{~mm}$. The asymmetry of the wall shear stress distribution with respect to the cross-section $Y=0$ appeared on the rear surface of the impeller. Correspondingly, the secondary flow had various strengths in the circumferential direction around the pivot. This was suggested to be because the computational calculation became somewhat unstable due to the large calculation volume relative to the small fixed pressure boundary set up at the volute and the outlet of the washout hole. This calculation instability could potentially be eliminated by a model with a wide calculation area.

The histogram in Fig. 19 shows the effect of the back gap width of the impeller on the wall shear stress on the 


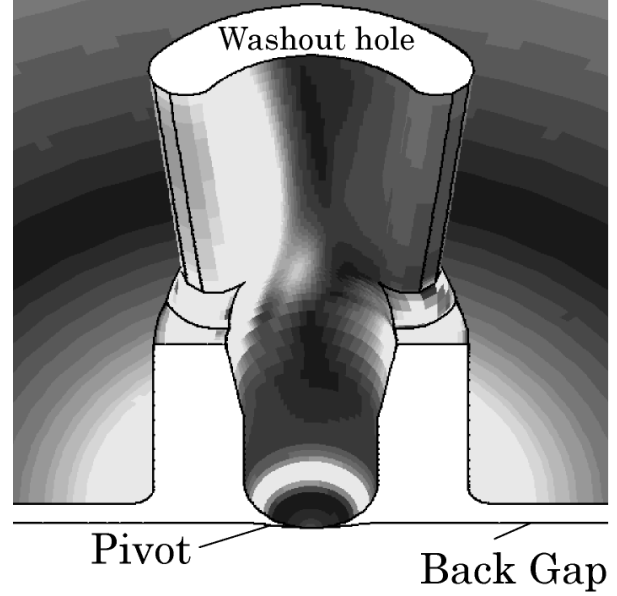

(a)

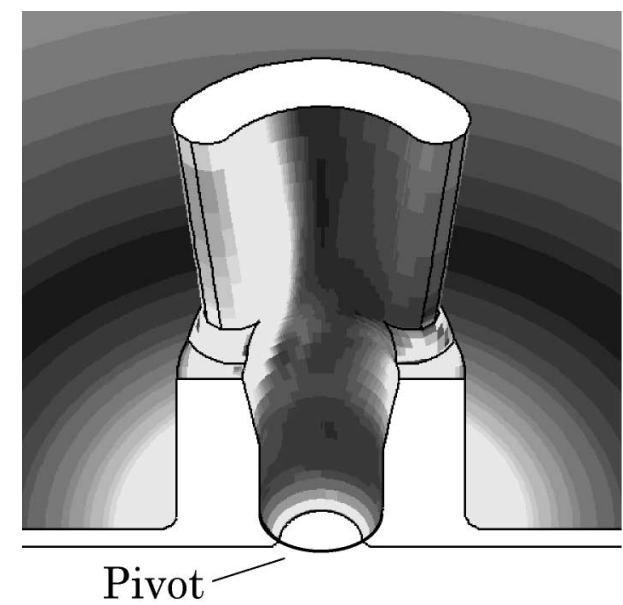

(c)

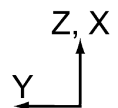

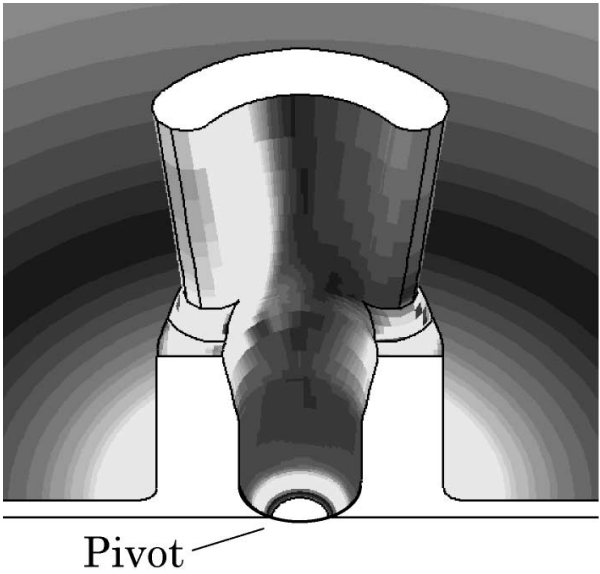

(b)

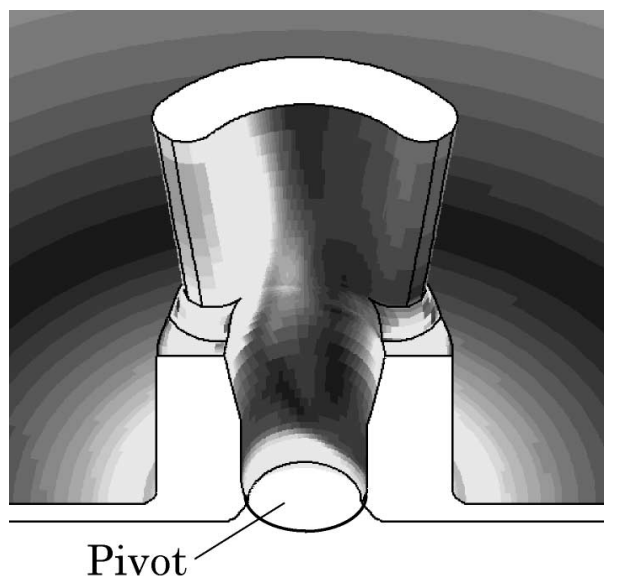

(d)

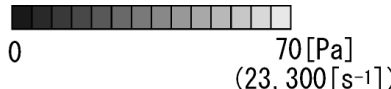

Fig. 12 Effect of the pivot friction area on the wall shear stress contour around the pivot bearing in the model DD9 series; (a) Pivot friction area, $a_{F}=0 \mathrm{~mm}^{2}$ (model DD8), (b) $a_{F}=1.6 \mathrm{~mm}^{2}$ (model DD10), (c) $a_{F}=3.6 \mathrm{~mm}^{2}$ and (d) $a_{F}=8 \mathrm{~mm}^{2}$ (model DD9)

surface of the male pivot in the model DD10 series. The peak wall shear stress of approximately $10-15 \mathrm{~Pa}$ gradually decreased, with both high and low wall shear stress regions also increasing substitutively and gradually as the back gap width of the impeller increased, reflecting the wall shear stress contour in Fig. 18.

3. 4 Effect of the geometry on the antithrombogenecity test results

Figure 20 shows the anti-thrombogenetic states around the pivot from the result of anti-thrombogenecity tests for some model geometries. These photos were taken around the pivot from the rear of the impeller. The model with a washout hole diameter of $9.8 \mathrm{~mm}$ (DD7), having a pivot friction area of $0 \mathrm{~mm}^{2}$ and a back gap width of the impeller of $0.6 \mathrm{~mm}$, was observed to have thrombus formation around the pivot. The model with the washout hole diameter that decreased to $7 \mathrm{~mm}$ (DD8) also had a thrombus formation around the pivot in some test results. Conversely, the model with the pivot friction area increased to $8 \mathrm{~mm}^{2}$ (DD9), having a washout hole diameter of $7 \mathrm{~mm}$ and a back gap width of the impeller of $0.6 \mathrm{~mm}$, was observed to have no thrombus formation around the pivot. Similarly, the model with a back gap width of the impeller that increased to $2.6 \mathrm{~mm}$ (MC101), having a washout hole diameter of $7 \mathrm{~mm}$ and the pivot friction area of $1.6 \mathrm{~mm}^{2}$, also had no thrombus formation around the pivot.

Table 3 shows a summary of the relationship between the model geometry and the results obtained from the anti-thrombogenecity tests. The results suggest that the model with a washout hole diameter of $7 \mathrm{~mm}$ (DD8) operated better than the model with a washout hole of $9.8 \mathrm{~mm}$ (DD7). Conversely, it was not apparent which 


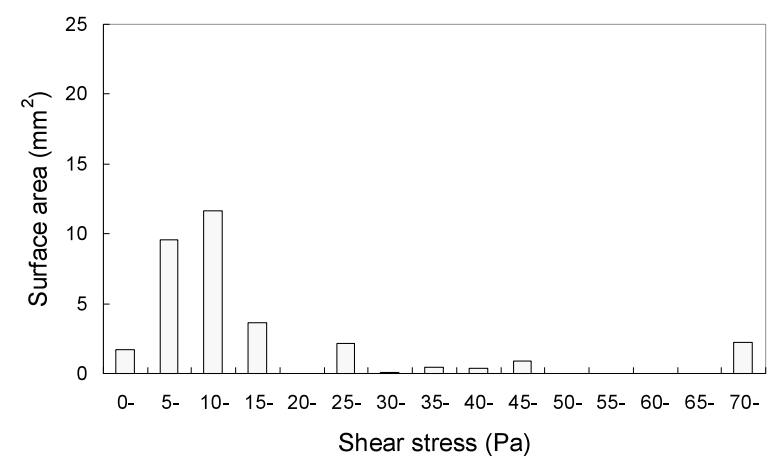

(a)

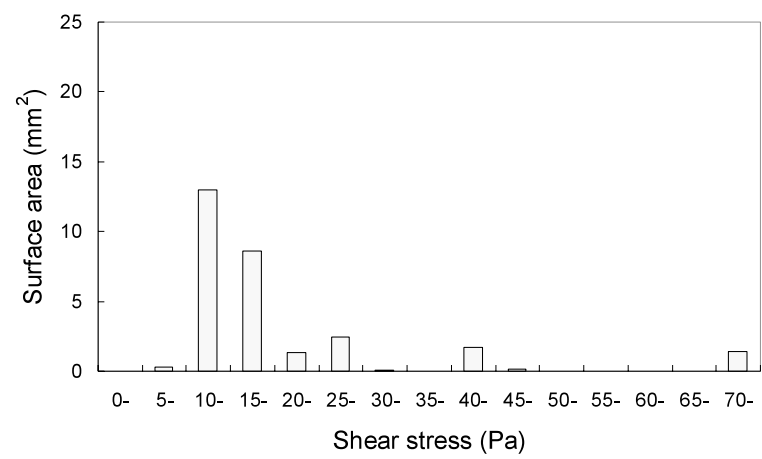

(c)

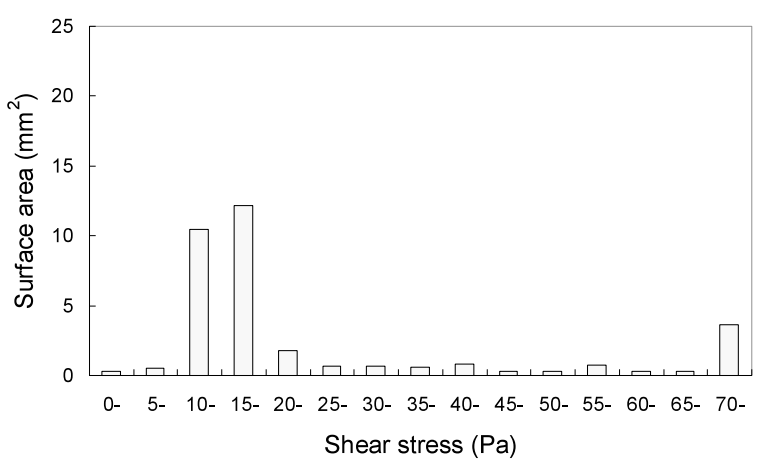

(b)

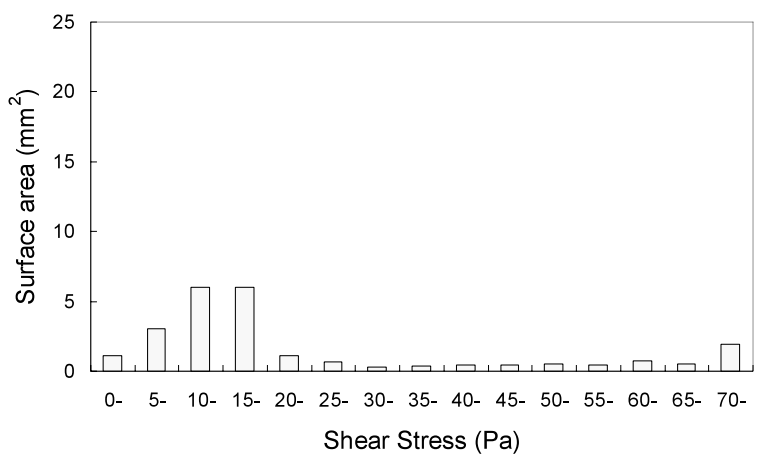

(d)

Fig. 13 Effect of the pivot friction area on the histogram of the wall shear stress of the pivot bearing in the model DD9 series; (a) Pivot friction area, $a_{F}=0 \mathrm{~mm}^{2}$ (model DD8, $a_{B}=33 \mathrm{~mm}^{2}$ ), (b) $a_{F}=1.6 \mathrm{~mm}^{2}$ (model DD10, $a_{B}=31 \mathrm{~mm}^{2}$ ), (c) $a_{F}=3.6 \mathrm{~mm}^{2}$ $\left(a_{B}=29 \mathrm{~mm}^{2}\right)$ and $(\mathrm{d}) a_{F}=8 \mathrm{~mm}^{2}\left(\operatorname{model} \mathrm{DD} 9, a_{B}=25 \mathrm{~mm}^{2}\right)$

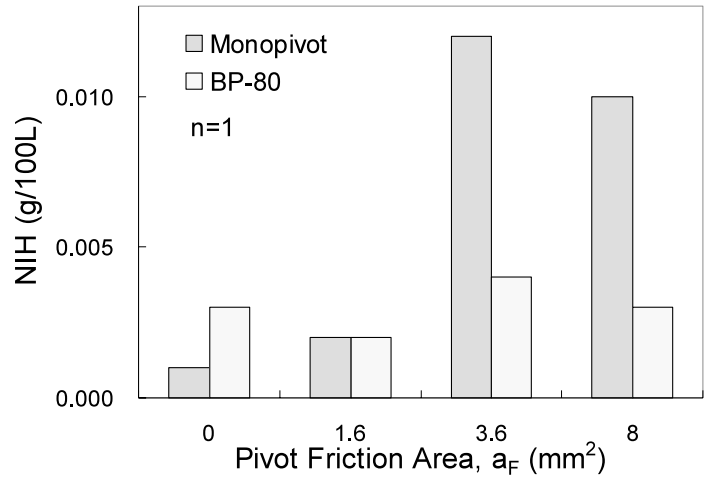

Fig. 14 NIH values obtained from hemolysis tests for the model DD9 series having various pivot friction areas

back gap width of the impeller was more efficient, $0.6 \mathrm{~mm}$ or $2.6 \mathrm{~mm}$. However, the model with the back gap width of the impeller of $2.6 \mathrm{~mm}$ (MC101) had almost no thrombus formation, indicating that models with a large back gap width of the impeller were geometrically sufficient.

\section{Discussion}

\subsection{Regarding the effect of the cross-sectional area of the washout hole and the back gap of the impeller}

The flow rate through the washout hole and the back gap of the impeller increases as the washout hole diame-

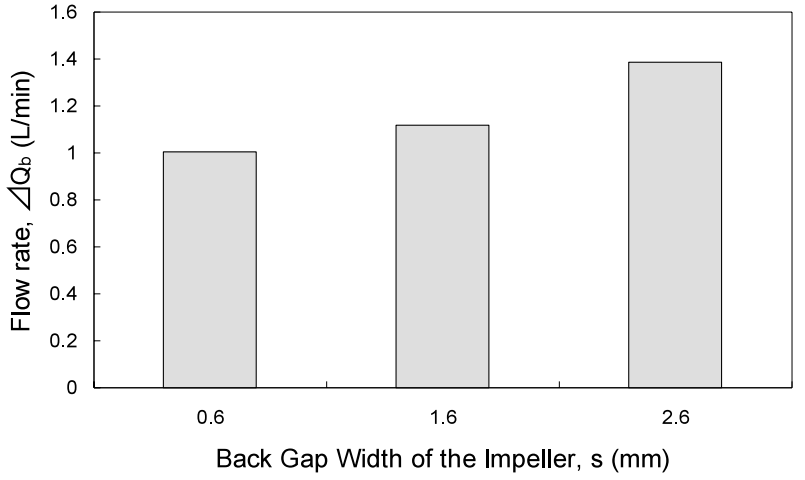

Fig. 15 Effect of the back gap width of the impeller on the flow rate through the washout hole and the back gap of the impeller in the model DD10 series (\#6, \#9, \#10 in Table 1. Washout hole diameter, $d=7 \mathrm{~mm}$, Pivot friction area, $a_{F}=1.6 \mathrm{~mm}^{2}$ )

ter increases (Fig. 5). As shown in Fig. 15, the flow rate through the washout hole and the back gap of the impeller also increases as the cross-sectional area of the back gap of the impeller increases. The effects of the washout hole diameter and the back gap width of the impeller are considered effects of the flow path resistances in the washout hole and the back gap of the impeller that depend only on the cross-sectional area of the flow path themselves in the present study since the pressure difference between the vo- 


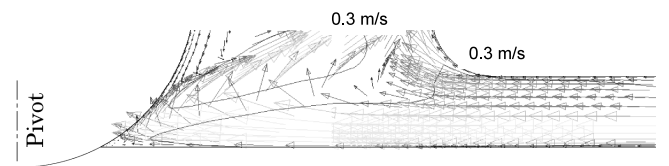

(a)

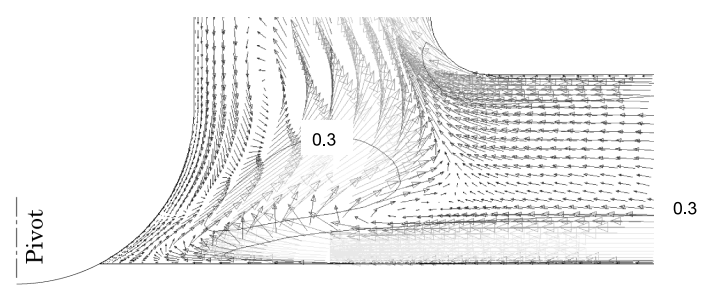

(b)

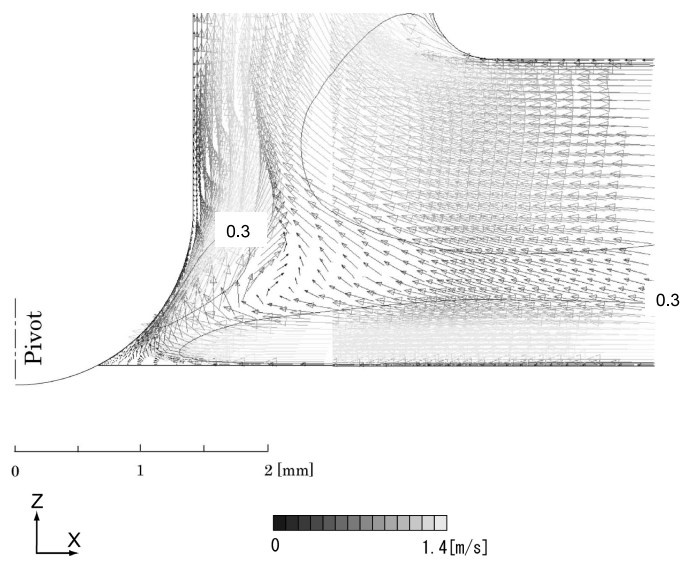

Fig. 16 Velocity distribution of the secondary flow in model MC101

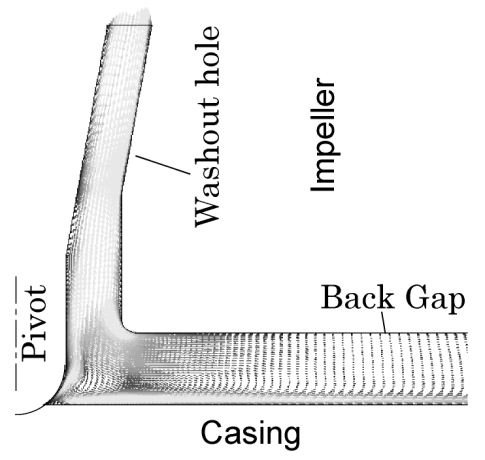

Fig. 17 Effect of the back gap width of the impeller on secondary velocity distribution around the pivot bearing in the model DD10 series; (a) Back gap width of the impeller, $s=0.6 \mathrm{~mm}$ (model DD10), (b) $s=$ $1.6 \mathrm{~mm}$ and (c) $s=2.6 \mathrm{~mm}$ (model MC101)

lute and the outlet of the washout hole coincide with each other. Therefore, the flow rate through the washout hole and the back gap of the impeller is dominated by the crosssectional area across the flow path from the volute to the outlet of the washout hole.

Figure 21 shows the distribution of the cross-sectional area across the flow path in the direction from the volute to the outlet of the washout hole for all models. Here, the

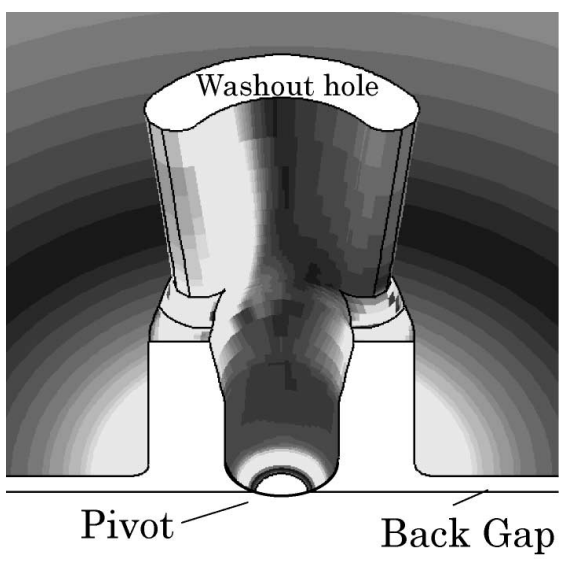

(a)

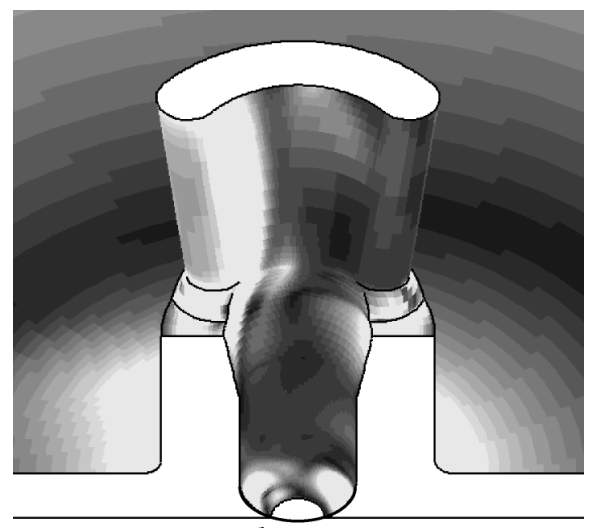

Pivot

(b)

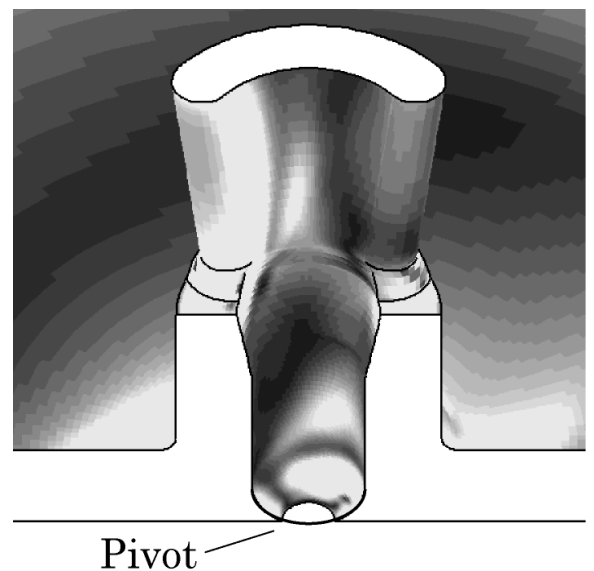

(c)
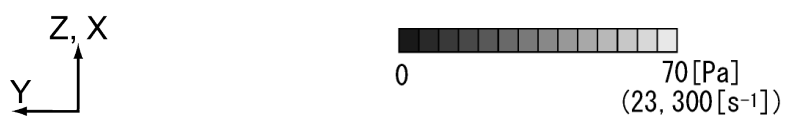

Fig. 18 Effect of the back gap width of the impeller on wall shear stress contour around the pivot bearing in the model DD10 series; (a) Back gap width of the impeller, $s=0.6 \mathrm{~mm}$ (model DD10), (b) $s=1.6 \mathrm{~mm}$ and (c) $s=2.6 \mathrm{~mm}(\operatorname{model} \mathrm{MC} 101)$ 


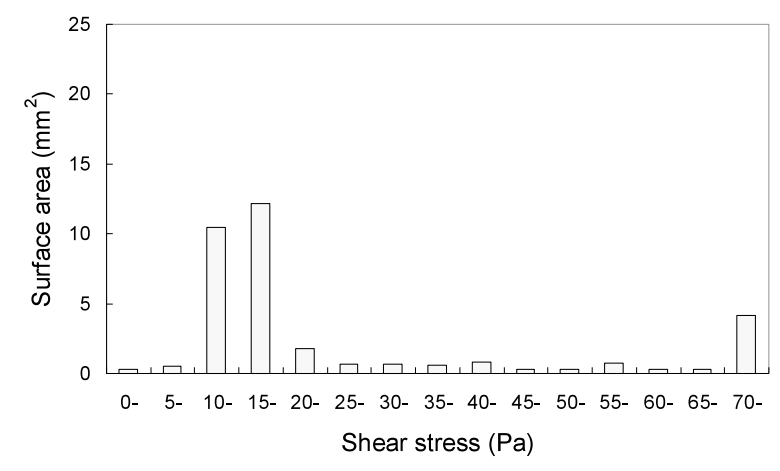

(a)

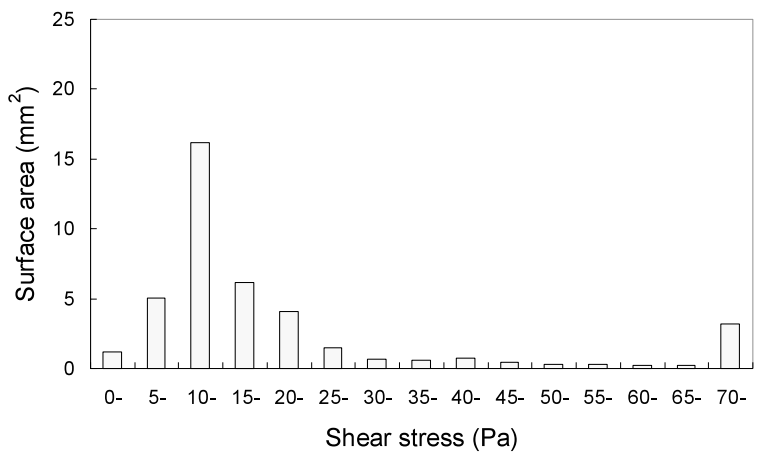

(b)

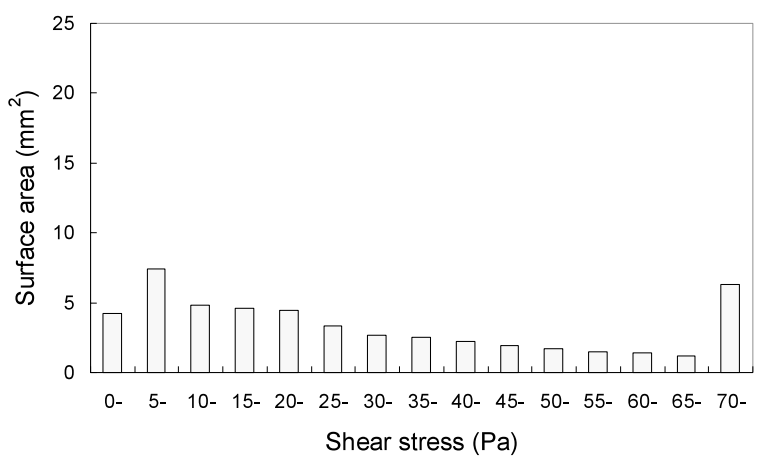

(c)

Fig. 19 Effect of the washout hole diameter on the histogram of the wall shear stress of the surface of the pivot bearing in the model DD10 series: (a) Back gap width of the impeller, $s=0.6 \mathrm{~mm}$ (model DD10, $a_{B}=31 \mathrm{~mm}^{2}$ ), (b) $s=1.6 \mathrm{~mm}\left(a_{B}=41 \mathrm{~mm}^{2}\right)$ and (c) $s=2.6 \mathrm{~mm}$ (model $\mathrm{MC} 101, a_{B}=50 \mathrm{~mm}^{2}$ )

direction from the volute to the outlet of the washout hole is defined as the $L$ direction (See Fig. 3 ). As the washout hole diameter decreased, the cross-sectional area across the flow path decreased slightly, and consequently the flow rate through the washout hole and the back gap of the impeller decreased slightly. On the other hand, as the back gap width of the impeller increased, the cross-sectional area across the flow path increased somewhat, which, contrary to expectation, increased the flow rate through the washout hole and the back gap of the impeller slightly. The reason for the slight increase in the flow rate through the back gap of the impeller is that the fluid easily receives a centrifugal force in the large back gap of the impeller, which eliminates the inward secondary flow.

Figure 22 shows the distributions of the crosssectional averaged velocity in the flow path in the direction from the volute to the outlet of the washout hole for all models. The cross-sectional averaged velocity is defined as the flow rate through the washout hole and the back gap of the impeller divided by the cross-sectional area of them. The cross-sectional averaged velocity in the washout hole increases as the washout hole diameter decreases because the flow path resistance in the washout hole relatively increases. On the other hand, the cross-sectional averaged velocity in the back gap of the impeller decreases as the back gap width of the impeller increases because of the relative decrease in path resistance in the back gap of the impeller. Therefore, the cross-sectional averaged velocity is primarily dominated by the relative flow path resistance in the washout hole to in the back gap of the impeller, which depends on each of their cross-sectional areas across the flow path.

Based on the results obtained from CFD analyses and animal experiments in our previous study, low wall shear stress (less than approximately $5 \mathrm{~Pa}$ ) was considered to be related to thrombus formation ${ }^{(5)}$. In order to decrease the occurrence of the stagnant region around the pivot bearing, the secondary flow in the back gap of the impeller should be used effectively to wash out the pivot bearing. For this purpose, the washout hole diameter and the back gap width of the impeller should be adjusted. The washout hole diameter should be decreased so as to reach the secondary flow to the pivot bearing, although the concomitant decrease in the flow rate through the washout hole need to be considered. Conversely, the back gap width of the impeller should be increased so as to increase the flow rate into the washout hole, while considering that this decreases the cross-sectional averaged velocity of the secondary flow through the back gap of the impeller.

\subsection{Regarding the effect of the pivot friction area}

As shown in Figs. 12 and 13, the stagnant region decreases as the pivot friction area increases. As mentioned previously, the stagnant region is thought to be related to thrombus formation. Therefore, from an antithrombogenetic point of view, the pivot friction area should be increased as was demonstrated in the comparison of DD8 and DD9 as shown in Table 3. However, the crush of the blood cell increases between the male and female pivots as the pivot friction area is increased as shown in Fig. 14. Therefore, an adequate pivot friction area should be decided in order to avoid both the stagnant region and increased hemolysis.

\section{Concluding Remarks}

The flow rate through the washout hole and the back gap of the impeller is dominated by the cross-sectional 


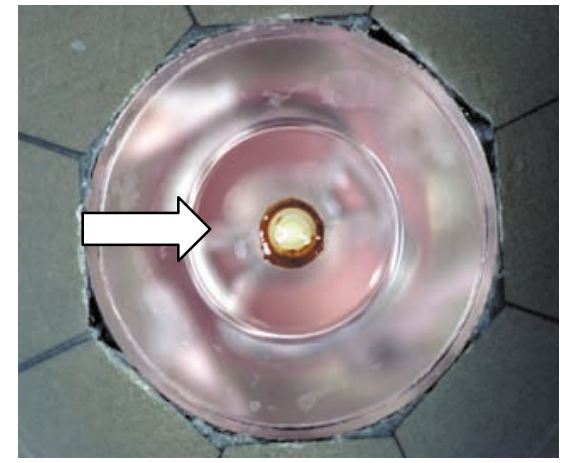

(a)

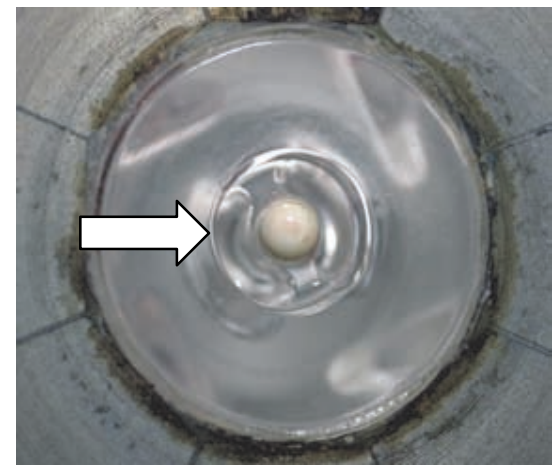

(c)

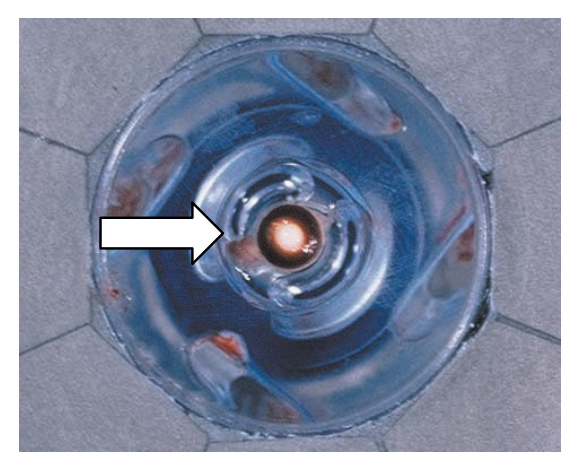

(b)

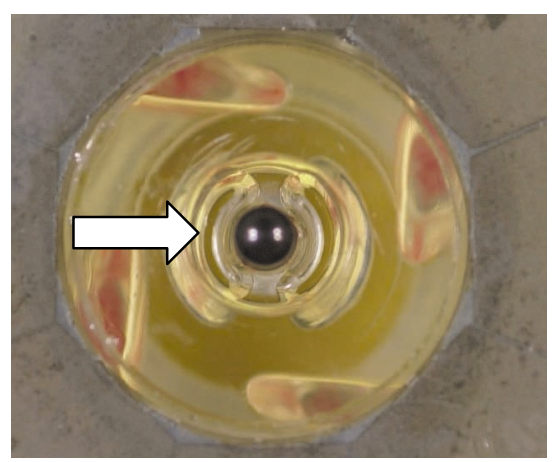

(d)

Fig. 20 Anti-thrombogenetic states around the pivot from the result of anti-thrombogenecity tests for several model geometries: (a) DD7 ${ }^{(9)}$, (b) DD8, (c) DD9 ${ }^{(9)}$ and (d) MC101

Table 3 Summary of the relationship between the model geometry and the result from animal experiments

\begin{tabular}{|c|cc|c|c|}
\hline ID & \multicolumn{2}{|c|}{ Name } & Thrombus locationsaround the pivot & $\begin{array}{c}\text { Number } \\
\text { of times }\end{array}$ \\
\hline$\# 1$ & DD7 & Rotating pivot & 2 \\
$\# 2$ & DD7-9 & --- & \\
$\# 3$ & DD7-8 & & --- & 3 \\
$\# 4$ & DD8 & (DD7-7) & Rotating pivot or None & \\
$\# 5$ & DD7-6 & & --- & $(3)$ \\
(\#4) & (DD8 & (DD7-7) & (Rotating pivot or None) & \\
$\# 6$ & DD10 & (DD9D) & --- & 2 \\
$\# 7$ & DD9C & & --- & \\
$\# 8$ & DD9 & (DD9A) & None & 1 \\
\hline (\#6) & (DD10 & (DD9D)) & --- & \\
$\# 9$ & MC101A & & --- & None \\
$\# 10$ & MC101 & & & \\
\hline
\end{tabular}

area across the flow path from the volute to the outlet of the washout hole.

The secondary flow that prevents stagnation around the pivot bearing depends on the relationship between the washout hole diameter and the back gap width of the impeller. A smaller cross-sectional area results in a larger secondary flow velocity in the region as a result of the comparison between that in the washout hole and that in the back gap of the impeller.

The velocity of secondary flow around the pivot bearing did not decrease greatly, even when the back gap width of the impeller was large, because secondary flow was concentrated in a layer measuring approximately $0.5 \mathrm{~mm}$ from the casing wall in the back gap of the impeller as a result of a centrifugal force caused by the impeller rotation.

Increasing the pivot friction area eliminates the stagnant region around the pivot clearance between the male and the female pivots but increases the hemolysis.

\section{References}

( 1 ) Hashimoto, S., Maeda, H. and Sasada, T., Effect of Shear Rate on Clot Growth at Foreign Surfaces, Artificial Organs, Vol.9, No.4 (1985), pp.345-350.

( 2 ) Affeld, K., Reininger, A.J., Gadischke, J., Grunert, K., Schmidt, S. and Thiele, F., Fluid Mechanics of the Stagnation Point Flow Chamber and Its Platelet Deposition, Artificial Organs, Vol.19, No.7 (1995), pp.597602.

( 3 ) Nakamura, S., Ding, W., Smith, W.A. and Golding, L.A.R., Numeric Flow Simulation for an Innovative Ventricular Assist System Secondary Impeller, ASAIO Journal, Vol.45, No.1 (1999), pp.74-78.

( 4 ) Burgreen, G.W., Antaki, J.F., Wu, J., Blanc, P. and Butler, K.C., A Computational and Experimental Comparison of Two Outlet Stators for the Nimbus LVAD, ASAIO Journal, Vol.45, No.4 (1999), pp.328-333.

( 5 ) Chan, W.K., Wong, Y.W., Yu, S.C.M. and Chua, L.P., A Computational Study of the Effects of Inlet Guide Vanes on the Performance of a Centrifugal Blood Pump, Artificial Organs, Vol.26, No.6 (2002), pp.534542. 


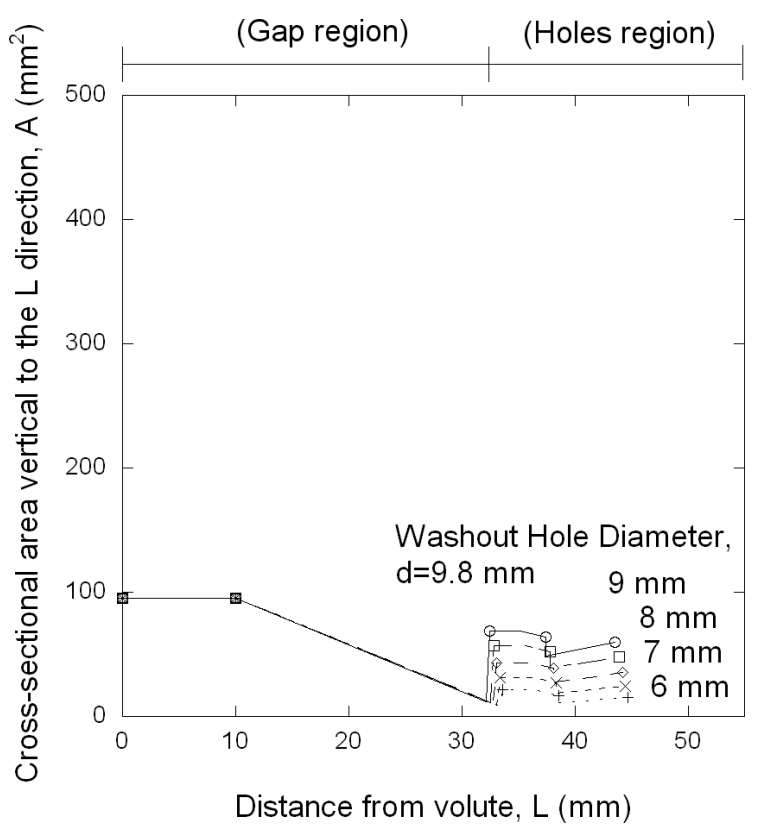

(a)

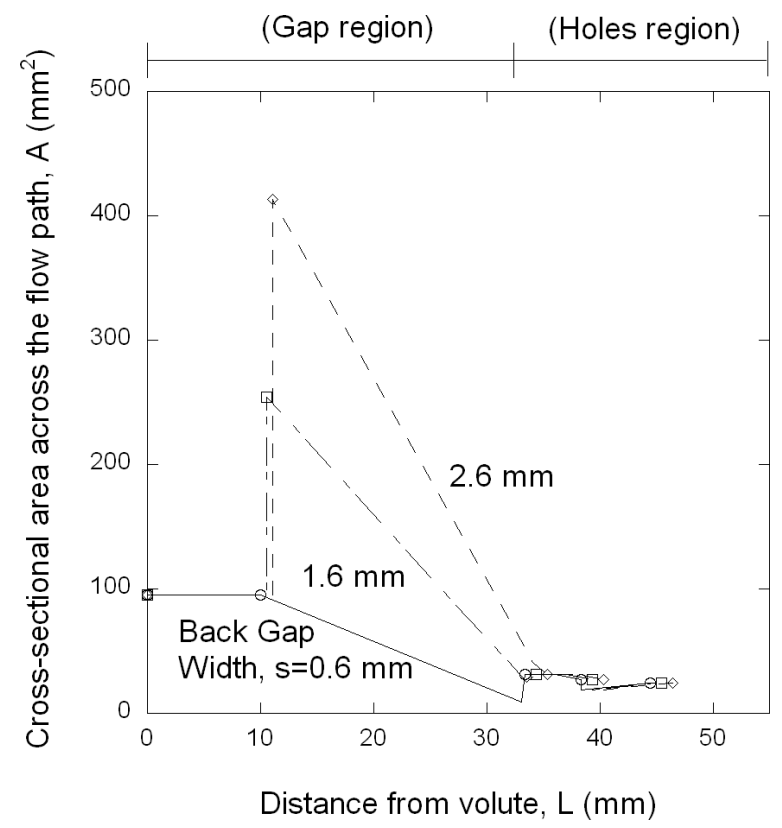

(b)

Fig. 21 Distributions of the cross-sectional area across the flow path from the volute to the outlet of the washout hole: (a) Variation of washout hole diameter and, (b) variation of the back gap width of the impeller

( 6 ) Chua, L.P., Ong, K.S., Simon, C.M. and Zhou, T., Leakage Flow Rate and Wall Shear Stress Distribution in a Biocentrifugal Ventricular Assist Device, ASAIO Journal, Vol.50, No.6 (2004), pp.530-536.

( 7 ) Yamane, T., Ikeda, T., Orita, T., Tsutsui, T. and Jikuya, T., Design of a Centrifugal Blood Pump with Magnetic Suspension, Artificial Organs, Vol.19, No.7 (1995), pp.625-630.

( 8 ) Nishida, M., Yamane, T. and Asztalos, B., Washout Hole Flow Measurement for the Development of a

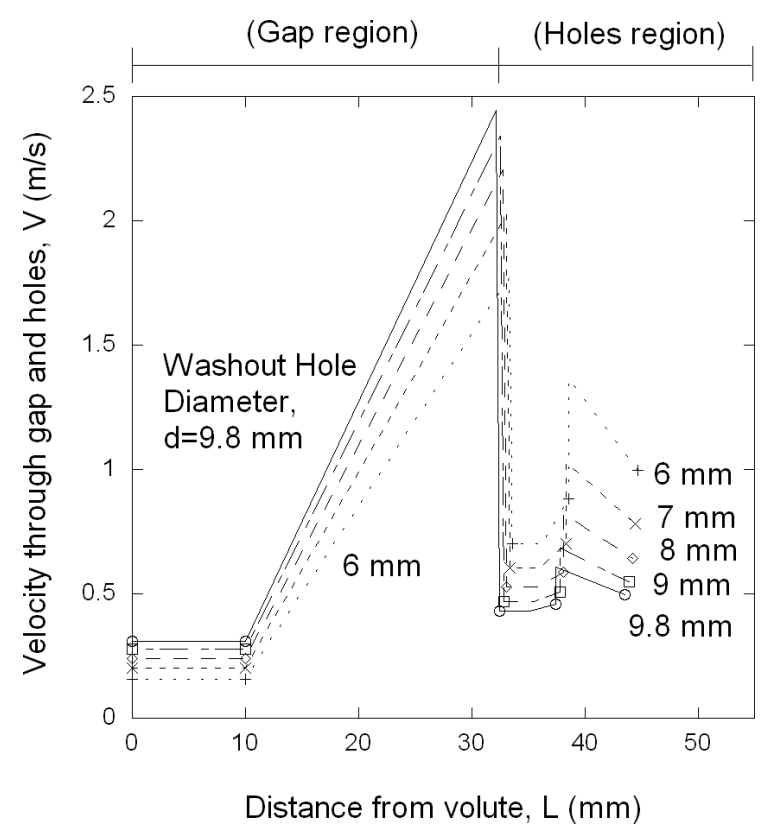

(a)

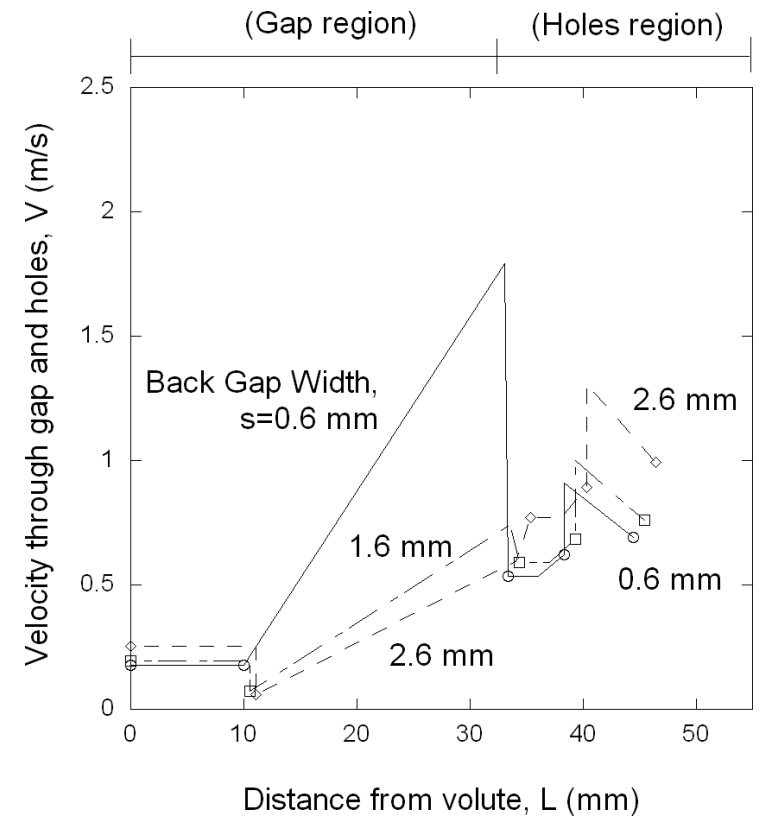

(b)

Fig. 22 Distributions of the cross-sectional averaged velocity in the flow path from the volute to the outlet of the washout hole; (a) Variation of washout hole diameter and, (b) variation of the back gap width of the impeller

Centrifugal Blood Pump, Artificial Organs, Vol.22, No.5 (1998), pp.386-392.

( 9 ) Toyoda, M., Nishida, M., Maruyama, O., Yamane, T., Tsutsui, T. and Sankai, Y., Geometric Optimization for Non-Thrombogenicity of a Centrifugal Blood Pump through Flow Visualization, JSME Int. J., Ser.C, Vol.45, No.4 (2002), pp.1013-1019.

(10) Yamane, T., Maruyama, O., Nishida, M., Toyoda, M., Tsutsui, T., Jikuya, T., Shigeta, O. and Sankai, Y., The Most Profitable Use of Flow Visualization in the Elim- 
ination of Thrombus fom a Monopivot Magnetic Suspension Blood Pump, Artificial Organs, Vol.28, No.4 (2004), pp.390-397.

(11) Nishida, M. and Yamane, T., Geometric Optimization for Non-Thrombogenicity of a Centrifugal Blood Pump through Computational Fluid Dynamic Analysis, JSME Int. J., Ser.C, Vol.47, No.4 (2004), pp.11081116.

(12) Yamane, T., Nishida, M., Kijima, T. and Maekawa, J., New Mechanism to Reduce the Size of the Monopivot Magnetic Suspension Blood Pump: Direct Drive Mechanism, Artificial Organs, Vol.21, No.7 (1997), pp.620-624.
(13) Maruyama, O., Nishida, M., Tsutsui, T., Jikuya, T. and Yamane, T., The Hemolytic Characteristics of Monopivot Magnetic Suspension Blood Pumps with Washout Holes, Artificial Organs, Vol.29, No.4 (2005), pp.345-348.

(14) Mizuguchi, K., Damm, G., Aber, G.A. Bozeman, R.J., Bacak, J.W., Svejkovsky, P.A., Orime, Y., Ohara, Y., Naito, K., Tasai, K., Makinouchi, K., Takatani, S., Nose, Y., Noon, G.P. and DeBakey, M.E., Does Hematocrit Affect in Vitro Hemolysis Test Results? Preliminary Study with Baylor/NASA Prototype Axial Flow Pump, Artificial Organs, Vol.18, No.9 (1994), pp.650656. 